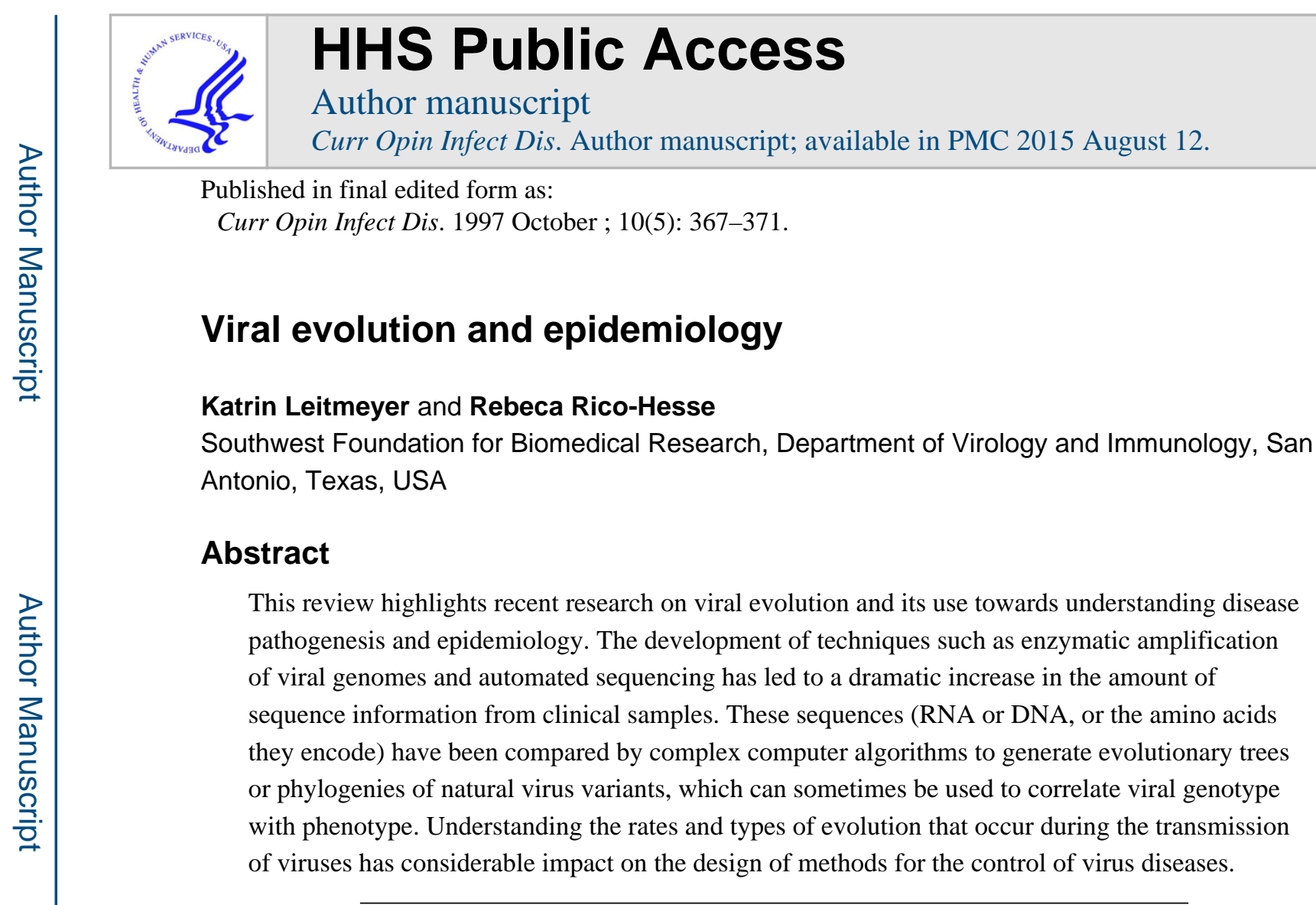

\title{
Introduction
}

The high genetic variability of viruses has been suspected for some time but only recent technical advances have allowed us to observe and describe this natural phenomenon. Because of the very large population of viruses circulating in host populations at any given time, even small changes in the genetic content of viruses could have a considerable impact on the way disease is manifested. Although viruses have one of the highest mutation rates of all organisms (presumably because they lack error-correcting mechanisms during replication), it is astounding how stable they are as a population or species, and how they continue to produce diseases which have been clinically described for decades or centuries. Viral mutation thus occurs at a high rate, on a regular basis, but we have not yet encountered many examples of rapid progression towards new phenotypes (or 'Andromeda' strains); changes in the pathogenesis or transmission of HIV-1, influenza A and Venezuelan equine encephalitis viruses may be caused by actual mutation events, but the clinical syndromes they cause remain relatively stable. It seems that the advent of modern day air travel and the urbanization/encroachment of humans on previously remote areas has had more impact on the public's health because they have led to a wider distribution of viral diseases and the emergence of viruses which were previously limited to other animal hosts (e.g. IIIV-1 and influenza A). Here we review reports on the molecular evolution of both RNA- and DNAcontaining viruses, and how their long- and short-term evolutionary trends can be interpreted epidemiologically, for an empirical approach towards improving viral disease diagnosis and control.

Address for correspondence: Dr Katrin Leitmeyer, Southwest Foundation for Biomedical Research, Department of Virology and Immunology, PO Box 760 549, San Antonio, TX 78245-0549, USA. 


\section{Constructing phylogenies}

The genetic or phylogenetic relationship among virus variants or strains can provide us with a wealth of information about how a virus is transmitted and what evolutionary selective pressures it undergoes. Understanding these relationships can help to determine which strains might be more virulent or efficiently transmitted, when and where these strains are originating, and under what ecological conditions, what virus(es) to use as the basis for a vaccine, and what host population should be targeted for vaccination or treatment. Therefore, the methods used to construct phylogenies should be selected carefully, and their interpretation should include a consideration of the assumptions and biases involved in these experimental approaches. Because we cannot possibly include representatives of all variants circulating in the natural population at a given time, nor include all of the genetic information in a complete viral genome, we must remember that these trees are approximations of reality. Most trees are thus designed to respond to a specific question and will give us limited information about a viral phenotype or biological characteristic.

Probably the most important decision in generating phylogenies is the nature of the sequence to be compared among strains $\left[1^{*}\right]$. Complete gene sequences or portions of genes may be used but the best choice will come from reconsidering the question to be answered. Are we looking for short or long term evolutionary trends? Do we want to see the effect of host immune selection or tissue tropism? Are we looking for transmission patterns or bottlenecks, or both? Do we want to detect recombination events? Are we looking for a 'molecular clock', to determine branching times? Is the nucleotide substitution rate of the virus gene known? The questions we ask and the assumptions we include in the comparisons will determine the complexity of the task and the limits of interpretation. Numerous computer programs have been written which perform the sequence comparisons; they use different mathematical and processing algorithms to generate the graphical representations of genetic relationships we know as trees. In short, they differ according to the number of assumptions or the information we know about the virus sequences to be compared. As long as we limit our interpretations to the major branching patterns they generate, most programs give us superimposable or similar trees. Often, because of the availability of ever increasing amounts of sequence data (character size and number of taxa), the choice of phylogeny program may be based on the attainable computing facilities (or time constraints).

\section{Limitations on tree interpretation}

One way of determining the validity of the resulting phylogenetic tree(s) is to apply statistical measures of confidence. Most of the phylogenies reviewed here use the 'bootstrap' resampling test to measure the probability that they reflect reality (i.e. confidence); a bootstrap value of over $70 \%$ has been empirically equated to a confidence level of more than $95 \%$. In general, this means that a branching pattern to the right of a node with a bootstrap value of less than $70 \%$ is not supported and the sequence or virus relationships are indeterminate. Therefore, those that have bootstrap values of $50 \%$ or less should probably not even be discussed; these values have often been seen in recent literature and they have led to unsupported interpretations $\left[2^{\circ}\right]$. 
Other common problems with interpretations have been caused by sampling bias [3,4], statistically questionable correlations [5] or too small a sample size; a widely publicized paper [ [2] used only one sample (and sequences ranging in size from $38-152$ bp) to demonstrate the origin of the 1918 influenza pandemic. Sometimes assumptions about the gene nucleotide substitution rates are included in the phylogeny program which might impact on the outcome $\left[6,7^{\circ}\right]$ such as tree branching pattern or bootstrap values, but the effect of these data are hard to evaluate. Great care should also be taken when interpreting relationships in terms of phenotype or biological properties [ $\left.8,9^{\circ}\right]$; this is probably the most difficult to evaluate, because we currently know little about the molecular determinants of complex biological characteristics [10].

\section{RNA virus evolution}

Viruses using RNA molecules as genomes have the highest mutation rates observed in vivo or in vitro. The fact that most natural populations or single clinical sample of these organisms consist of a range of genetic variants has led to their description as a 'quasispecies'. When we analyse RNA sequences we should therefore keep in mind that we are looking at representatives of a normal distribution of genotypes; the area under the normal curve (number and type of variants) varies from one virus family or species to another.

\section{Retroviridae}

Human immunodeficiency virus type 1 -The largest number of papers concerned this virus and its classification into genetic subtypes on the basis of the comparison of different genes (env, gag, pol, vpr, vpu) or regions within a gene (env). New variants from Malaysia, Indonesia, Martinique, Cameroon and Nigeria have been classified on the basis of env sequences [10-14], whereas the classification on the basis of pol sequences seems to be more stable in time $\left[15^{\circ}, 16\right]$. The comparison of classification schemes on the basis of both env and gag sequences demonstrated the existence of hybrid or recombinant HIV-1 viruses in Thailand [17'], whereas the comparison of phylogenies using complete versus partial env gene sequences detected probable recombination sites within this region of the genome $\left[18^{\circ}\right]$.

To investigate the association of nucleotide deletions in the nef gene with attenuation further, HIV-1 viruses from a large group of patients with differing clinical presentations were analysed, and no correlation was found between defective nef genes and disease state in nine out of 10 patients $\left[1^{\circ}\right]$. The relationship between disease progression and the genetic diversity of HIV-1 was studied in perinatally infected children; where the evolution of a portion of the nev gene seemed to reflect positive selection for change in children with slow disease progression $\left[20^{\circ}\right]$. Three epidemiologically linked individuals were sampled over 8 years to determine evolution rates and selective pressures on the V3 loop of env [21], and there was evidence for strong selection towards mutation at the amino acid level, thus supporting the Darwinian natural selection hypothesis.

Human T-cell lymphotropic virus type II-Analysis of the X-V/rof gene region of 16 samples from different Indian groups in North, Central and South America suggested that 
two distinct subtypes of human T-cell lymphotropic virus (HTLV)-II viruses were brought by tribes migrating to the New World, and that the origin of the subtype infecting intravenous drug users in the USA is still unknown [22 $2^{\circ}$.

\section{Orthomyxoviridae}

Studies of the genetic relationships of influenza A viruses, using nucleotide sequences of the neuraminidase gene, support the existence of two distinct lineages that are being transmitted around the world; strains currently used for the preparation of vaccines represent both lineages, and this approach should be used as a basis for future strain selections [23].

\section{Flaviviridae}

Hepatitis C-Mutation rates in the E1 and NS5B genes were estimated from a known transmission cohort, and this information was then used to calculate divergence times for the known hepatitis $\mathrm{C}$ virus (HCV) genotypes (types 1-6); after careful consideration of the limitations of this interpretation, the conclusion was that HCV subtypes have been evolving independently for 500-2000 years [24].

Yellow fever-Three different gene regions of 13 yellow fever virus isolates from Africa and South America were compared; four distinct lineages were observed and the distinct evolution and transmission of African viruses led to the conclusion that this group was introduced to the Americas $\left[25^{\circ}\right]$.

\section{Filoviridae, Bunyaviridae, Arenaviridae, Togaviridae}

Ebola-The analysis of Ebola isolates from recent outbreaks in Zaire and the Ivory Coast and the comparison of sequences encoding the glycoproteins demonstrated the extreme stability of this virus in nature, after almost 20 years of transmission; this suggests that this virus has coevolved with its as yet unknown reservoir host [26*0].

Hantavirus-A literature review [27] containing a section on hantavirus evolution concludes that the phylogenetic relatedness (based on $\mathrm{S}$ segment sequences) between these viruses resembles that of their natural hosts (rodents).

Arenaviruses-Phylogenetic analysis of a portion of the nucleocapsid $(\mathrm{N})$ gene of all Tacaribe complex arenaviruses revealed three-distinct lineages, one of which seems to segregate on the basis of human pathogenic potential [ $\left.28^{\circ}\right]$. The comparison of another portion of the $\mathrm{N}$ gene was used to classify a newly deseribed human pathogen, Sabiá virus [29].

Alphaviruses-Western equine encephalitis strains from the New World were shown to be of recombinant origin when sequences from the E1 glycoprotein gene and those from the nonstructural protein nsP4 were compared $\left[30^{\circ}\right]$. Enzootic, equine-avirulent Venezuelan equine encephalitis viruses were shown to be the source of epidemic/epizootic strains which caused a very large outbreak in Colombia and Venezuela in 1995; the mechanisms leading to the generation of these equine-virulent viruses seem to include point mutation and selection [31]. 


\section{DNA virus evolution}

In general, DNA viruses show fixation of mutation (in the natural population) at rates much lower than those for RNA viruses (on average, one mutation in every $10^{8}$ nucleotides copied versus one in every $10^{4}$, respectively). These differences are presumably caused by processing mechanisms of the viral replicating enzymes, with DNA polymerases having additional proofreading activities. In spite of this conservation in genome structure, researchers have found regions with higher mutation frequencies that can be used to distinguish strains.

\section{Papovaviridae}

A comprehensive study of human papillomaviruses from cervical specimens collected around the world gave reliable estimates of the genetic variability in a portion of the L1 open reading frame (major capsid protein); because these viruses use the host cell DNA polymerase for replication, it seems that the virus phylogenies may reflect host (human) population evolution and dynamics [32].

\section{Herpesviridae}

The initial characterization of a virus associated with Kaposi's sarcoma demonstrated its probable classification as a gamma-2 herpesvirus (genus Rhadinovirus), and this is the first member of this genus which has been shown to infect humans; comparison of amino acids from nine open reading frames to corresponding genome regions of 11 other herpesviruses allowed the classification of this new agent $\left[33^{\circ}\right]$.

\section{Conclusion}

The exponential increase of available sequence data will lead to further interpretations of phylogenies towards understanding the epidemiology of viral diseases. Researchers should, however, be aware of the limitations of comparing mutation rates across genes that undergo different selective pressures. Without the elucidation of the mechanisms leading to virus variant selection in nature, the conclusions we reach may not reflect the true complexity of evolution.

\section{Abbreviations}

HCV hepatitis C virus

HTLV human T lymphotropic virus

\section{References and recommended reading}

Papers of particular interest, published within the annual period of review, have been highlighted as:

- of special interest

$\bullet$ of outstanding interest 
1••. Ohno T, Mizokami M, Saleh MG, Orito E, Ohba K-1, Wu R-R, Koide T, Tibbs CJ, Nouri-Aria KT, Tokudome S, Williams R. Usefulness and limitations of phylogenetic analysis for hepatitis C virus core region: application to isolates from Egyptian and Yemeni patients. Arch Virol. 1996; 141:1101-1113. Sequence comparison of only a short fragment of the HCV core region was shown to give a different genotype classification than analysis of a greater number of $\mathrm{HCV}$ isolates or analysis of a different genomic region. [PubMed: 8712927]

2•. Taubenberger JK, Reid AH, Krafft AE, Bijwaard KE, Fanning TG. Initial genetic characterization of the 1918 "Spanish" influenza virus. Science. 1997; 275:1793-1796. Very small RNA fragments from different regions of the genome from a single individual who died during the 1918 influenza pandemic were sequenced to conclude that a novel H1N1 influenza A virus was discovered. [PubMed: 9065404]

3. Kuiken CL, Cornelissen MTE, Zorgdrager F, Hartman S, Gibbs AJ, Goudsmit J. Consistent risk group-associated differences in human immunodeficiency virus type vpr, vpu and V3 sequences despite independent evolution. J Gen Virol. 1996; 77:783-792. [PubMed: 8627267]

4. Lukashov VV, Goudsmit J. Founder virus population related to route of virus transmission: a determinant of intrahost human immunodeficiency virus type 1 evolution? J Virol. 1997; 71:20232030. [PubMed: 9032334]

5. Narwa R, Roques P, Courpotin C, Parnet-Mathieu F, Boussin F, Roane A, Marce D, Lasfargues G, Dormont D. Characterization of human immunodeficiency virus type $1 \mathrm{p} 17$ matrix protein motifs associated with mother-to-child transmission. J Virol. 1996; 70:4474-4483. [PubMed: 8676472]

6. Van de Peer Y, Janssens W, Heyndrickx L, Fransen K, van der Groen G, de Wachter R. Phylogenetic analysis of the env gene of HIV-1 isolates taking into account individual nucleotide substitution rates. AIDS. 1996; 10:1485-1494. [PubMed: 8931782]

7•. Rodrigo AG, Mullins JI. Human immunodeficiency virus type 1 molecular evolution and measure of selection. AIDS Res Hum Retrovir. 1996; 12:1681-1685. Two different methods for estimating positive selection were described: calculation of the ratio of the proportions of synonymous (ds)/non-synonyrnous (dn) substitutions, and the difference between ds and dn substitutions may lead to different conclusions regarding the existence of selective pressures. [PubMed: 8959243]

8. Hughes ES, Bell JE, Simmonds P. Investigation of the dynamics of the spread of human immunodeficiency virus to brain and other tissues by evolutionary analysis of sequences from the p17gag and env genes. J Virol. 1997; 71:1272-1280. [PubMed: 8995651]

9•. Wong JK, Ignacio CC, Torriani F, Havlir D, Fitch NJS, Richman DD. Invivo compartmentalization of human immunodeficiency virus: evidence from the examination of pol sequences from autopsy tissue. J Virol. 1997; 71:2059-2071. In this study, $700 \mathrm{bp}$ fragments of the reverse transcriptase region of different tissue specimens from four zidovudine-resistant patients were analysed. Brain-derived sequences appeared to be phylogenetically distinct from spleen and lymph node-derived sequences. Anatomically distinct, selective pressures are suggested. [PubMed: 9032338]

10. Howard TM, Rasheed S. Genomic structure and nucleic sequence analysis of a new HIV type 1 subtype A strain from Nigeria. AIDS Res Hum Retrovir. 1996; 12:1413-1425. [PubMed: 8893049]

11. Takehisa J, Zekeng L, Miura T, Ido E, Yamashita M, Mboudjeka I, Gurtler LG, Hayami M, Kaptue L. Triple HIV-1 infection with group $\mathrm{O}$ and group $\mathrm{M}$ of different clades In a single Cameroonian AIDS patient. J Acquir Immune Defic Syndr. 1997; 14:81-82.

12. Desgranges C, Fillon S, Neisson-Vernant C, Bera O, Ouka M, Cesaire R, Buzelay L, Barin F. Presence of HIV-1 subtype B and F and HTLV-1 HIV/HTLV coinfected individuals in Martinique. J Acquir Immune Defic Syndr. 1996; 13:468-470.

13. Porter KR, Mascola JR, Hupudio H, Ewing D, VanCott TC, Anthony RL, Corwin AL, Widodo S, Ertono S, McCutchan FE, et al. Genetic, antigenic and serologic characterization of human immunodeficiency virus type 1 from Indonesia. J Acquir Immune Defic Syndr. 1997; 14:1-6.

14. Brown TM, Robbins KE, Sinniah M, Saraswathy TS, Lee V, Hooi LS, Vijayamalar B, Luo C-C, Ou C-Y, Rapier J, et al. HIV type 1 subtypes in Malaysia include B, C, and E. AIDS Res Hum Rotrovir. 1996; 12:1655-1657. 
15•. Soto-Ramirez LE, Tripathy S, Renjifo B, Essex M. HIV-1 pol sequences from India fit distinct subtype pattern. J Acquir Immune Defic Syndr. 1996; 13:299-307. Phylogenetic analysis of pol nucleotide sequences of five HIV-1-positive individuals revealed that all isolates clustered in a new subtype, designated as $C$; this was consistent with previous findings based on envelope sequences. With steadily increasing diversification of HIV viruses phylogenetic analysis of more conserved regions such as pol might offer another option for classification.

16. Zheng NN, Hurren L, Neilan BA, Cooper DA, Delanoy SF, McQueen PW. Sequence analysis of the reverse transcriptase region of HIV type 1 isolate from Sydney, Australia. AIDS Res Hum Retrovir. 1996; 12:1731-1732. [PubMed: 8959251]

17. Carr JK, Salminen MO, Koch C, Gotte D, Artenstein AW, Hegerich PA, St Louis D, Burke DS, McCutchan FE. Full-length sequence and mosaic structure of a human immunodeficiency virus type 1 isolate from Thailand. J Virol. 1996; 70:5935-5943. The full genome sequence of one mosaic virus from Thailand revealed multiple genetic origins. Matrix genes (the entire gag-pol region and most of the accessory genes vif, vpr, tat, rev and vpu) seem to be derived from clade A, but outer envelope genes from clade E. [PubMed: 8709215]

18•. Gao F, Morrison SG, Robertson DL, Thornton CL, Craig S, Karlsson G, Morgado M, GalvaoCastro B, von Briesen $\mathrm{H}$, et al. Molecular cloning and analysis of functional envelope genes from human immunodeficiency virus type 1 sequence subtypes A through G. J Virol. 1996; 70:16511667. Phylogenetic analysis of the full-length env gene sequences detected recombinants that have not been detected in previous analyses of the partial env sequence. [PubMed: 8627686]

19•. Ratner L, Josephs T, Bandres J, Ghosh S, Vander Heyden N, Templeton A, Hahn B, Powderly W, Arens M. Sequence heterogeneity of nef transcripts in HIV-1 infected subjects at different stages of disease. Virology. 1996; 223:245-250. Phylogenetic analysis of 30 nef gene sequences from 10 HIV-1-infected persons with different disease status did not reveal a correlation between phylogenetic position of the nucleotide sequences and the disease state of the individual from whom they were derived; the role of the nef gene as a major determinant of pathogenicity should be questioned. [PubMed: 8806559]

20•. Ganeshan S, Dickover RE, Korber BM, Bryson YJ, Wolinsky SM. Human immunodeficiency virus type 1 genetic evolution in children with different rates of development of disease. J Virol. 1997; 71:663-677. Viral diversification and evolution were monitored by phylogenetic analysis of the C2-V5 region of the env gene for six perinataily infected children. Distinctively greater genetic distances were observed for the viral sequences obtained from children with slow disease progression, as opposed to children with rapid progression presenting relatively conserved, monophyletic populations of genotypic variants that persisted over lime. The finding of a higher rate of non-synonymous substitutions in slowly progressing children suggests that HIV-1 quasispecies populations evolve under natural selection constraints. [PubMed: 8985398]

21. Zhang L, Diaz RS, Ho DD, Mosley JW, Busch MP, Mayer A. Host-specific driving force in human immunodeficiency virus type 1 evolution in vivo. J Virol. 1997; 71:2555-2561. [PubMed: 9032400]

22•. Biggar RJ, Taylor ME, Neel JV, Hjelle B, Levine PH, Black FL, Shaw GM, Sharp PM, Hahn BH. Genetic variants of human T-lymphotropic virus type II in American Indian groups. Virology. $1996 ; 216: 165-173$. In this study a 780-bp fragment of the X-V/rof region was used to determine the genetic relationships of HTLV-II strains infecting geographically diverse Indian populations. It is suggested that ancestral Amerindians migrating to the New World more than 15000 years ago brought at least two types of HTLV-II viruses, subtypes lla and 1lb, with them. The conservation of these viral sequences may indicate that HTLV-II is a very ancient virus of man, which may have adapted to persist in humans without causing serious disease. [PubMed: 8614983]

23. Xu X, Cox NJ, Bender CA, Regnery HL, Shaw MW. Genetic variation in neuraminidase genes of influenza A (H3N2) viruses. Virology. 1996; 224:175-183. [PubMed: 8862412]

24. Smith DB, Pathirana S, Davidson F, Lawlor E, Power J, Yap PL, Simmonds P. The origin of hepatitis C virus genotypes. J Gen Virol. 1997; 78:321-328. [PubMed: 9018053]

25•. Wang E, Weaver SC, Shope RE, Tesh RB, Watts DM, Barrett ADT. Genetic variation In Yellow fever virus: duplication in the $3^{\prime}$ non-coding region of strains from Africa. Virology. 1996; 225:274-281. Phylogenetic analyses of the $5^{\prime}$ terminus, the NS4A/B, and the $3^{\prime}$ terminus regions 
of 13 yellow fever isolates suggest the existence of four distinct genotypes. Duplication in the $3^{\prime}$ non-coding region was only observed for the wild-type isolates. [PubMed: 8918913]

26••. Sanchez A, Trappier SG, Mahy BWJ, Peters CJ, Nichol ST. The virion glycoproteins of Ebola viruses are encoded in two reading frames and are expressed through transcriptional editing. Proc Natl Acad Sci USA. 1996; 93:3602-3607. Phylogenetic analysis of the entire glycoprotein genes revealed that the recent Ivory Coast outbreak represents a fourth subtype of the Ebola virus. The isolate from the $1995 \mathrm{Kikwit}$ outbreak, however, was virtually identical to the virus that almost 20 years earlier caused an epidemic in Yambuku, Zaire, supporting the theory that Ebola viruses are very old viruses that have slowly coevolved within their natural reservoirs. [PubMed: 8622982]

27. Plyusnin A, Vapalahti O, Vaheri A. Hantaviruses: genome structure, expression and evolution. J Gen Virol. 1996; 77:2677-2687. [PubMed: 8922460]

28. Bowen MD, Peters CJ, Nichol ST. The phylogency of New World (Tacaribe Complex) arenaviruses. Virology. 1996; 219:285-290. A phylogenetic analysis of a 613-649-bp region of the conserved region of the nucleocapsid $(\mathrm{N})$ protein gene of all known Tacaribe complex arenaviruses revealed three distinct lineages $(\mathrm{A}-\mathrm{C})$ with all human pathogenic viruses clustering in lineage B. [PubMed: 8623541]

29. Gonzalez JPJ, Bowen D, Nichol ST, Rico-Hesse R. Genetic characterization and phylogeny of Sabia virus, an emergent pathogen in Brazil. Virology. 1996; 221:318-324. [PubMed: 8661442]

30•. Weaver SC, Kang W, Shirak Y, Rumenapf T, Strauss EG, Strauss JH. Recombinational history and molecular evolution of western equine encephalomyelitis complex alphaviruses. J Virol. 1997; 71:613-623. A phylogenetic tree based on 477 nucleotides from the $\mathrm{C}$ terminus of the E1 envelope glycoprotein gene (which for western equine encephalomyelitis is derived from a Sindbis-like parent) indicated that all members of the serocomplex comprise a monophyletic group with four major lineages. Another classification based on a 517-nucleotide sequence at the $\mathrm{C}$ terminus of the nsP4 gene (which in western equine encephalomyelitis virus was derived from eastern equine encephalomyelitis-like virus parent) indicated that all New World western equine encephalomyelitis complex viruses except Aura virus are recombinants derived from eastern equine encephalomyelitis and Sindbis-like ancestors, unlike the Old World members which did not appear to have recombinant genomes. [PubMed: 8985391]

31. Weaver SC, Salas R, Rico-Hesse R, Ludwig GV, Oberste S, Boshell J, BTR. Re-emergence of epidemic Venezuelan equine encephalomyelitis in South America. Lancet. 1996; 348:436-440. [PubMed: 8709783]

32. Stewart A-CM, Eriksson AM, Manos MM, Munoz N, Bosch FX, Peto J, Wheeler CM. Intratype variation in 12 human papillomavirus types: a worldwide perspective. J Virol. 1996; 70:31273136. [PubMed: 8627792]

33•. Moore PS, Gao SJ, Dominguez G, Cesarman E, Lungu O, Knowles DM, Garber R, Pellett PE, McGeoch DJ, Chang Y. Primary characterization of a herpesvirus agent associated with Kaposi's sarcoma. J Virol. 1996; 70:549-558. This initial characterization of a new virus associated with Kaposi's sarcoma demonstrated that the agent is probably a gamma-2 herpesvirus, representing the first member of this genus causing infection in humans. [PubMed: 8523568] 